\title{
O DISPOSITIVO TÉCNICO
}

Franz Josef Brüseke*

\section{O TEMPO DA VIDA}

A vida é somente um episódio entre as longas horas do nascimento e as horas da morte, por ventura não menos demoradas. A repetição da vida individual, digamos, horizontalmente, nos bilhões de vidas dos seus contemporâneos não dissolve essa situação; muito menos consola o fato de que a vida individual pode ser vista, verticalmente, integrada na longa corrente de vidas da própria espécie. A vida está sendo vivida de forma singular e tem uma "viva consciência" da sua singularidade e finitude. "Consciência viva" significa experimentar o mundo, pensando, e fazer dela através dessa nossa vida uma "experiência" . Na medida em que a consciência não consegue mais vincular a sua própria finitude com uma cosmologia que transcende 0 seu horizonte, temporalmente limitado, desperta o interesse pelo próprio corpo. Ele é o veículo da experiência do mundo, e o tempo a sua disposição é o tempo da duração dessa experiência. Entre as frustrações centrais, no sentido da narzistische Kränkung (frustração narcisista) de Sigmund Freud, trazidas pela concepção moderna do mundo, configura a descoberta da diferença entre o tempo à disposição do indivíduo e o tempo deste mundo. O paradigma do tempo absoluto, da mecânica de Newton, expressa teoricamente uma nova concepção da physis e radicaliza essa mágoa, sentida pelo homem moderno, pois o tempo absoluto e teoricamente infinito é o tempo do mundo e não o tempo da sua vida; ainda contribui para a frustração do homem o fato que o tempo absoluto é, em princípio, reversível o que o tempo do homem não é.

* Mestre e doutor em Sociologia pela Westfälische Wilhelms Universität Münster na Alemanha. Professor da Universidade Federal de Santa Catarina. (bruseke@brturbo.com.br) 


\section{O TEMPO DO MUNDO}

O tempo do mundo parece uma eternidade, também depois de saber que $o$ universo existe há provavelmente 16 bilhões de anos , em comparação com as poucas décadas dadas ao indivíduo. Esse começa a ter a sensação de que o tempo é escasso. Bens escassos são, em tempos modernos, o objeto de economias e cálculos. $\mathrm{O}$ homem que sabe que the resta pouco tempo calcula o tempo com a intenção de poder prolongar o seu tempo de vida. O tempo da vida, que possibilita e limita o tempo da sua experiência do mundo, também está sendo submetido a uma intensificação. O desejo de querer fazer mais experiência em menos tempo corresponde à nova economia que requer mais trabalho em menos tempo e concorre com o tempo livre do trabalhador (SCHULZE, 1992). Somente o tempo livre parece garantir alegria e lazer, fazendo assim, da jornada do trabalho um roubo daquele tempo à disposição do assalariado. Aparecem, no horizonte da sociedade industrial do século XIX, as primeiras grandes lutas pelo tempo! (NEGT, 1988) Este fenômeno seria somente uma curiosidade antropológica, se ele não expressasse a essência da sociedade moderna e sua relação com o tempo, o da vida e o do mundo. $O$ fato de que a experiência do mundo, durante a vida plena, está sendo delegado ao tempo livre, onde experiência significa "experimentar" novas sensações, diminui a qualidade e autenticidade dessa experiência; substitui, assim, o roubo pela perda do tempo; o "homem experiente" sabe disso.

$\mathrm{O}$ mundo que se tornou experiência exige todo tempo do homem, ou pior, ele demanda mais tempo do que a própria vida oferece. A rivalidade entre o tempo do mundo e o tempo da vida, da qual Hans Blumenberg fala (BLUMENBERG, 1986, p. 27) tem nisso sua força motriz. O filósofo da virada copernicana nos relata os sintomas dessa "patologia": “... pressa nos ganhos de tempo, que a vida tenta extrair através de artifícios e truques, até as hipervelocidades do mundo tecnológico (technoid), além da transferência momentânea de informações e simulações, valores de gozo e de emoções a distância, atualizações do sucumbido como daquilo que está por vir.” (BLUMENBERG, 1986, p. 27) A aceleração faz com que as coisas percam a sua "naturalidade" ou "normalidade"; o que se transforma com uma velocidade aquém da capacidade de percepção do 
homem de identificar mudanças fica sem registro e, assim dizer, não possui "história".

\section{ARTIFICIALIDADE}

O caráter invasivo que muitos autores atribuem ao aparecimento de corpos técnicos no meio da normalidade e naturalidade, na verdade, não se restringe somente à técnica. Podemos até dizer que certos artefatos foram absorvidos pelo mundo da vida até o ponto que se transformaram na "segunda" natureza do homem. E, pelo contrário, "estranha" o homem freqüentemente fenômenos que são manifestações evidentemente naturais. Em caso de dúvida, ele acha hoje seu par de sapatos mais "natural" do que um relâmpago e uma escada rolante parece mais "familiar" do que uma onça andando solta no shopping-center.

Rafael Capurro (1995/2005) observa que o século XIX foi fascinado pela natureza e a história; hoje exerceria a artificialidade, o mesmo fascínio sobre as pessoas. Partindo dessa premissa pergunta: qual é o sentido do artificial e em especial das novas tecnologias eletrônicas, e qual é a relação entre 0 artificial e outros "entes" como a natureza, a transcendência e o próprio homem?

Para responder suas perguntas, que visam a uma melhor compreensão do conceito da "artificialidade", retornamos nos tempos. Já a filosofia grega conheceu a distinção entre o natural e 0 artificial. Em geral podemos dizer que existiam, para os gregos, coisas originadas pela própria natureza (physis) e coisas geradas pelo homem (poieisis), como instrumentos de trabalho ou obras de arte. No processo da produção artística imita 0 artista a natureza (mimesis); mais precisamente: 0 artista não imita aquilo que já se encontra na natureza, mas imita como a natureza "produz". Diferente da natureza, o artista tem que refletir sobre a finalidade de um objeto e tem que saber também como conseguir alcançar essa finalidade. Graças ao saber técnico, ele pode atribuir à sua obra um caráter, de certo modo, liberado da finalidade, i.e., a beleza. A artificialidade no sentido grego seria então a identidade entre a utilidade e o Bem (agathos) e aquilo sem finalidade, o Belo (kalos). O demiurgo platônico dispõe sobre as formas divinas e é capaz de criar a natureza em uma maneira muito mais perfeita 
do que o homem. Este último, na verdade, produz somente cópias quando, por exemplo, molda uma estátua.

A tradição judaico-cristã conhece também um Deus artístico e criador, mas, diferente dos gregos, consegue este criar as coisas do nada (creatio ex nihilo). Somente Deus é capaz de criar do nada; o homem e a própria natureza somente conseguem dar uma nova forma àquilo que já existe. Essa concepção ficou válida durante toda Idade Média e atribuiu somente a Deus a qualidade de criador (creatio). O homem, ele mesmo criatura, ficou dependente da criação divina, é na concepção de Tomas de Aquino o contingens (lat.), algo contingente (AQUINO, 1996).

Pois, retornando mais por alguns momentos ao caminho da argumentação de Rafael Capurro, surge no renascimento e no início dos tempos modernos uma concepção do homem que atribui a ele cada vez mais qualidades de um criador. Este homem criador é genial na medida em que ele, além de reproduzir as coisas conforme as regras dadas, é capaz de gerar novas regras. No ato da geração de novas regras relaciona-se o homem, de uma ou outra maneira, com o divino. Este pensamento, sobre a centralidade do fazer artístico e sobre a relação íntima entre o gênio e a dimensão metafísica, encontramos em Goethe e Schiller e, em termos gerais, na literatura e na poesia romântica. O século XIX, com Marx e Feuerbach, deveria "naturalizar" a produção estética e nos apresentar uma concepção de um "artista secularizado" e um "trabalhador industrializado" (CAPURRO, 2005).

A profanização da arte abre a possibilidade da sua politização; fato largamente explorado na primeira metade do século XX. Neste tempo e mais precisamente no interludium bellicum entre 1918 e 1939, articulase uma compreensão da técnica por um lado emancipada de qualquer dimensão metafísica e artística (a técnica enquanto meio para alcançar determinados fins) e por outro lado um recarregamento da técnica com uma promessa salvacionista, utópica ou heróica, não obstante, totalmente absorvida por uma concepção materialista do mundo, concebido enquanto campo de batalha. 


\section{RUPTURA SEMÂNTICA}

São numerosas as críticas à técnica moderna que acelerava a sensação de perda do tempo valorizando-a economicamente. Em 1936 apresenta Charles Chaplin seu filme Modern Times e Aldous Huxley publica em 1932 seu romance Brave New World, uma utopia negativa de um mundo desumanizado e racionalizado, dominado pela técnica. Tanto Huxley como Chaplin reagem com meios artísticos à filosofia da linha de montagem, apresentado por Henry Ford na sua obra My Life and Work, já em 1922. Essa filosofia tinha uma base bem real. Em 1923 produziu Ford dois milhões de exemplares do legendário modelo "T", o Tin Lizzie, com um método sofisticado de divisão e cooperação de trabalho, nestas dimensões não conhecido até então. Apesar da crise da Ford Company, somente quatro anos mais tarde, abriu Henry Ford o caminho da produção industrial em série e em grande quantidade. A denominação Fordismo representa até hoje emblematicamente a época da automação industrial, que aplicou até as últimas conseqüências o lema do aumento da produtividade do trabalho: time is money. É essa mudança dramática no mundo do trabalho e nas grandes aglomerações urbanas que inspiram os escritores, poetas, dramaturgos e até músicos. Nos anos vinte, Bertold Brecht, Alexander Döblin e muitos outros cineastas e literatos estetizam, com intenção crítica, o grande Moloch da modernidade técnica, assim denominado e apresentado no filme Metrópolis, por Fritz Lang. Este Moloch já tinha mostrado na primeira guerra mundial (1914-1918) as suas garras de aço. Pois não foi a questão ambiental e tampouco a questão social que despertou uma primeira onda de reflexão e crítica à técnica moderna, mas a sua introdução, em larga escala, enquanto dispositivo mortal.

Podemos observar hoje, de uma segura distância de um século, nestes anos da primeira guerra mundial, o começo de uma ruptura semântica, profunda, irreversível e de várias dimensões. No contexto da nossa reflexão sobre a modernidade e a técnica podemos registrar somente alguns aspectos dela, entre eles, em primeiro lugar, a crise, desde então crônica, da própria filosofia do progresso. Essa filosofia interpretava a história humana como um caminho difícil, mas orientado por um telos, por um objetivo, que assegurava tanto a sua transparência científica, como sua disponibilidade 
técnica crescente, além de garantir um happy end para seus atores, seja este imaginado como a sociedade sem classes, em que cada um vivia na base da igualdade segundo suas necessidades, ou seja ele concebido como um futuro do "bem-estar", da "emancipação" e "auto-realização" ou, não por último, como palco da realização da cidadania plena e livre, assegurada por um Estado de direito.

A filosofia do progresso possui uma relação positiva com a ciência e a técnica e se faz presente no marxismo e em praticamente todas as outras correntes teóricas e políticas do século XIX. Uma das raras exceções é a linha de pensamento que passa por Schopenhauer e Nietzsche. No entanto, a filosofia do progresso sofre um revés devastador, como reflexo imediato da experiência da aplicação da racionalidade instrumental, como força destrutiva, no campo da batalha. Este, racionalizado e abastecido com artefatos bélicos em escala industrial, relativiza as virtudes do guerreiro de outrora, e coloca-o como operador e alvo em contato íntimo com a técnica. Em conseqüência da experiência de perda, tendem derrotados à interpretações realistas, se não pessimistas, da situação. Seja o que for a sua causa, assistimos na Alemanha depois da Primeira Guerra Mundial, com mais força de expressão do que na Inglaterra, França ou nos Estados Unidos, o surgimento de uma crítica à sociedade moderna que ultrapassa a já corriqueira crítica ao capitalismo. Referente à sua abrangência temática, o novo espírito crítico estende seus questionamentos ao todo da civilização ocidental, i.e., à cultura (Kultur) como ela é concebida na língua alemã, e inclui a técnica no seu leque temático.

No entanto, as vozes não são uníssonas. Antes da segunda guerra misturam-se cenários de uma decadência do ocidente (Oswald Spengler) com um heroísmo do trabalhador, oriundo do marxismo, e um heroísmo do soldado, vindo do militarismo, que se misturam paradigmaticamente em Ernst Jünger e são, também, presentes na cultura oficial da jovem União Soviética e do nacional-socialismo alemão. O espírito da época exala uma fascinação ambígua pela técnica moderna, já que tanto o operário como o soldado são, a partir de agora, também: técnicos. A Segunda Guerra (39-45) aprofundou tanto o trauma da derrota como a experiência com as possibilidades destrutivas da técnica. Martin Heidegger vai sofisticar, 
depois da tempestade de aço (Stahlgewitter, E.Jünger), a reflexão sobre a técnica moderna e apresentar a questão da técnica no contexto de uma crítica fundamental ao pensamento (metafísico) ocidental. Sem que isso fosse ainda necessário, sintetizaram, em 1945, as explosões de artefatos nucleares em Hiroshima e Nagasaki a urgência dessa questão. A ruptura semântica se completou e, a partir daí, não é mais possível descrever a técnica moderna no vocabulário (ingênuo) da filosofia do progresso.

\section{O DISPOSITIVO TÉCNICO}

Heidegger apresenta um conceito ampliado da técnica que compreende não somente seu caráter enquanto mero instrumento e meio dos nossos propósitos mas como uma maneira de "desocultamento". A forma específica, i.e., técnica deste "desocultamento" faz com que a técnica moderna somente apresente determinadas possibilidades do Ser, no entanto, não consegue acessar sua "verdade" plena. Heidegger tenta condensar a essência do desocultamento técnico no conceito "Gestell". Este neologismo quer transmitir que a técnica é tanto uma "armação" como uma manifestação da disposição do homem moderno de demandar somente aquilo da natureza que interessa economicamente ou pode ser usado funcionalmente em contextos mais diversos. Passando cinqüenta anos, podemos constatar que esse neologismo de Heidegger, apesar da sua mensagem inicial bastante inovadora, não se fixou nos debates sobre a técnica moderna. Achamos oportuno fazer uma proposta conceitual que conserva as intenções heideggerianas sem, por tanto, reproduzir as dificuldades comunicativas oriundos da denominação "Gestell". Usamos em seguir a expressão "dispositivo técnico" não como uma proposta de tradução do neologismo citado mas como um conceito que deve a Heidegger seu significado fundamental incorporando ao mesmo tempo novos significados que ultrapassam e ampliam a filosofia da técnica formulada por Heidegger nos moldes da ontologia fundamental.

Partindo do impulso inicial da filosofia da técnica de Heidegger, sem negar contribuições importantes de autores como Weber, Gehlen, Horkheimer, Adorno, Marcuse, Virilio, entre muitos outros, podemos apontar as seguintes características do dispositivo técnico: 
1. racionalização (cientificização; metafísica)

2. materialização (profanização)

3. homogeneização (igualização)

4. quantificação (medição)

5. funcionalização (sistematização)

6. manipulação (administração)

7. fabricação (industrialização)

8. imposição (antropocentrismo)

9. aceleração (modernização)

10. deslocação (globalização)

11. reprodução (cópia, serialização)

12. substituição (homo proteticus)

13. construção (desconstrução)

14. virtualização (realismo)

15. plasticidade (resistência)

16. emergência (desaparecimento)

\section{(1) racionalização}

A técnica moderna é impensável sem a ciência moderna, por vezes até confundem-se os dois, o que justifica para alguns autores falar hoje de uma técno-ciência. Até a palavra tecnologia une as palavras gregas techné e o logos e dá a entender que a técnica moderna, assim denominada, contém "lógica”, “razão" e "cálculos". Nem precisamos falar sobre "bombas inteligentes" para apontar algo que hoje já possui um certo grau de obviedade, i.e., a íntima relação entre ciência moderna e técnica moderna. $\mathrm{Na}$ verdade não é somente a técnica que incorporou elementos científicos, a própria ciência é técnica, quando usamos o termo técnica suficientemente abrangente. Empregamos tanto técnica quando lemos, escrevemos e, o que é mais grave, quando pensamos. E temos que ir além, nós não usamos somente a técnica, sob condições modernas pensamos tecnicamente. Isso é o caso quando experimentamos nos nossos laboratórios, quando 
colecionamos dados, quando relacionamos um dado com o outro ou quando calculamos as probabilidades da emergência de eventos que nos interessam. Pensar tecnicamente significa, também, livrar-se da inexatidão, do ilógico, do antinômico e do paradoxal. Com uma palavra: pensar tecnicamente significa ser racional. Heidegger suspeita que o pensar neste sentido não é mais, apesar dos procedimentos tecnicamente corretos, um pensar no seu sentido autêntico. Apesar de todos os avanços científicos, assim diz o autor, "nós ainda não pensamos". Se "a ciência não pensa", o que ela faz?

A ciência moderna é somente a outra metade da técnica moderna, na medida em que ela reproduz na sua estrutura interna o que é próprio da técnica. Outros denominaram a razão aplicada desta maneira "razão técnica” (MARCUSE, 1965) ou "razão instrumental”, conceito que indica a íntima relação da razão científica com os instrumentos, como nos fala da instrumentalização da própria razão por fins alheios. A crítica à razão instrumental, em Horkheimer e Adorno, ainda sugere a possibilidade da emancipação da razão do seu status moderno de mero instrumento e o jovem Jürgen Habermas, ainda andando nos passos dos seus mestres, identifica interesses que guiariam o processo da busca de conhecimento, estes interesses que movem a ciência seriam de natureza técnica, prática e emancipatória (HABERMAS, 1965/1968). Mais tarde, Habermas vai nos apresentar a razão comunicativa como contrapeso a razão instrumental. Deixamos em aberto se esta pode nos mostrar como sair do mundo dominado pela instrumentalidade. Habermas mesmo parece ver nela mais uma aliada para fortalecer a linha de defesa contra a colonização do mundo da vida pela lógica sistêmica da economia e da administração do que uma garantia de uma emancipação radical, da qual o jovem Marx sonhava.

O dispositivo técnico mesmo depende do processo da racionalização. Essa dependência é tão profunda que podemos freqüentemente até inverter a relação. Quer dizer, a própria racionalização depende do desenvolvimento do dispositivo técnico e se confunde freqüentemente com ele. A análise de Max Weber do racionalismo ocidental e a interpretação de Heidegger da metafísica européia elucidam com nitidez o contexto no qual o dispositivo técnico nasceu e se fortaleceu. Todas as outras características deste dispositivo vão nos remeter de uma ou outra forma a questão da metafísica 
e do racionalismo ocidental. O dispositivo técnico é, também, uma forma de pensar.

\section{(2) materialização}

A técnica não precisa recorrer a um discurso antimetafísico para revelar sua natureza plenamente "mundana”. A técnica tem uma relação meramente "física" com seu ambiente e consigo mesmo; aliás sob a perspectiva técnica torna-se tudo somente matéria, a ser transformada em material dos propósitos mais diversos. Para um cientista moderno, cujo mundo é exclusivamente "material”, possui a fala da materialização pouco sentido, pois pressupõe que seria possível transformar algo em matéria, que não é matéria; no entanto, "materializar" denomina, sim, o processo de tornar algo "material” que não o é plenamente. O dispositivo técnico evoca exatamente isso: ele apresenta o Ser somente enquanto "matéria" e sugere que este seja plenamente acessível sendo tratado de maneira "técnica". O ser humano, visto e tratado conforme o dispositivo técnico é, igualmente, um ser materializado, neste caso entendido e manipulado como um depósito de órgãos, genes, moléculas e átomos. Em uma palavra: o homem materializado não possui "alma". Historicamente, o conceito de materialização tem sua correspondência no processo da profanização que desapropriou o mundo da sua proteção pelo sagrado, pelos espíritos ou pelo tabu e outras prescrições inibidoras, que remeteram de uma forma ou outra aos fenômenos poderosos de origem “imaterial”. É curioso que a própria magia, apesar das suas referências constantes ao mundo imaterial, abriu o caminho para um tratamento técnico da natureza. (BRÜSEKE, 2004)

\section{(3) homogeneização}

O céu que era o abrigo dos deuses é agora distância a ser percorrida pelos satélites. Uma parte dele que identificamos através da mediação de altura como mais próximo transforma-se em atmosfera, indispensável para os processos de metabolismo na terra, e, tecnicamente falando, um depósito de elementos gasosos. Alguns destes aproveitamos para suprir demandas especiais, assim engarrafamos oxigênio para aliviar disfunções 
respiratórias ou preocupamo-nos com um, assim chamado, buraco de ozônio. Preocupamo-nos, porque não queremos adquirir um câncer de pele em conseqüência do excesso de raios ultravioletas que, assim dizem os cientistas, passam por este "buraco" com mais facilidade. O céu, véu enigmático da terra-mãe em outros tempos, está vazio, no entanto, cheio de artefatos que lançamos em qualquer hora, repleto de ondas e sinais que codificam as nossas vozes e transmitam imagens de um continente para o outro. Para o dispositivo técnico é o céu uma "matéria" entre outras; é mero espaço onde cada lugar pode ser descrito por um cruzamento de coordenadas, ele é um conjunto de signos no GPS. Este artefato diferencia os lugares com precisão, não obstante, homogeniza-os no exato momento da sua significação. A significação do lugar, com meios técnicos, não tem significado além de identificar um posicionamento. Para o dispositivo técnico não existe um lugar privilegiado. Podemos até dizer que o lugar, sob condições da modernidade técnica, desaparece, dando um enigmático sentido novo à utopia. $U$ topos quer dizer em grego: "nenhum lugar". A modernidade técnica é uma sociedade utópica, pois ela não tem "lugar". Ela não possui cultura e língua, não tem memória, não tem o cheiro do lar. O niilismo europeu, criticado filosoficamente e combatido fanaticamente pelos fundamentalismos mais diversos, é mais do que a relativização moral ou a ausência de valores últimos. Este "niilismo" tem como sua base o dispositivo técnico que através da homogeneização do espaço tende a anular "o lugar" e mais do que isso, tende, através da aceleração de qualquer processo de mudança, aniquilar o tempo próprio e substituí-lo pelo tempo da aceleração, i.e., o tempo do desaparecimento.

\section{(4) quantificação}

A quantificação é um procedimento que transforma qualidades de maneira que estas podem, com suporte matemático, ser descritas como variáveis numéricas e submetidas a operações de cálculo. Resultado da quantificação é a valorização de respostas que seguem a pergunta: quanto? Paralelamente ocorre a desvalorização de respostas resultantes da pergunta: como? O problema da quantificação foi largamente debatido na controvérsia sobre o positivismo na sociologia alemã, sem que isso mudasse o rumo 
das ciências positivas ou da própria sociologia que parece absorver, desde então, cada vez mais métodos "empíricos e estatísticos", impensáveis sem a quantificação de "dados".

O dispositivo técnico precisa de inputs quantitativos e tende, devido a sua lógica intrínseca, a substituir qualidades por quantidades. Parece impossível transformar determinadas qualidades, como a complexidade e profundidade de uma argumentação filosófica, por exemplo, em quantidade. Não obstante, os currículos científicos padronizados, como o Lattes, conseguem "traduzir" tanto os textos mais espirituosos como os mais achatados em números. Os "indicadores de produtividade" informam sobre a quantidade de publicações, mas não sobre sua qualidade. O que chamamos reconhecimento social parece depender cada vez mais dessas quantidades, que informam sobre o "peso" científico e social de alguém.

\section{(5) funcionalização}

O movimento racionalizante do dispositivo técnico sistematiza os elementos no seu ambiente segundo o critério da funcionalidade para seus próprios fins. No mundo dominado pelo dispositivo, somente sobrevive 0 que é funcional (ou irrelevante). No processo da funcionalização, torna-se aquilo que é disfuncional (ou até então irrelevante), funcional. Não por acaso a engrenagem é tida, por muito tempo, a metáfora da modernidade técnica. A engrenagem é a expressão do funcionamento de cada um dos seus elementos que estão sendo movidos e movem outros, conforme padrões preestabelecidos. O fascínio pelo funcionamento influenciou tanto a teoria social como práticas institucionais modernas. Até os grandes contra-projetos ao capitalismo, do século XIX e XX, se renderam ao mito da máquina (Mumford) na tentativa de realizar mecanismos de controle econômico e político que, no entanto, não funcionavam.

Curiosamente encontra o dispositivo técnico nos limites da funcionalidade seu maior desafio. Este é tanto técnico, como legitimatório. Técnico, na medida em que a exigência apropriada direcionada a técnica é que ela funcionasse. Legitimatório, na medida em que o funcionamento da técnica é o que sustenta a modernidade técnica. Falhas morais dos políticos ou imperfeições do seu sistema jurídico ou representativo suporta 
a sociedade contemporânea ad nauseam (dos mais sensíveis); a falta de energia elétrica, o break down do sistema de comunicação etc. colocam imediatamente em cheque aquilo do qual a modernidade técnica mais depende: seu funcionamento.

\section{(6) manipulação}

Agente principal da manipulação é a mão humana. Ela, atrelada a curiosidade da sua mente, concebe as coisas e leva-as até os seus olhos. Da percepção das perspectivas variadas, inerentes a cada objeto, surge a percepção das possibilidades ainda não exploradas. A vontade de combinar diferente, cortar em pedaços, desmontar, moldar e pintar, jogar longe ou deixar em lugar diferente, juntar com outros objetos, enfileirar ou montar etc. são somente algumas das possibilidades que emanam da habilidade da mão e das qualidades do objeto encontrado. O que move a manipulação parece o princípio: porque deixar algo assim, que também pode ser diferente? Ela é guiada pelo desejo de descontextualizar e transformar. De certo modo, a manipulação é o contraponto ao veredicto "deixar ser" encontrada nas filosofias e culturas contemplativas. Contemplar deriva-se das palavras latinas cum templum ("com o templo") o que pode dar a contemplação o significado: colocar algo nas circunferências do divino. A manipulação interrompe a ordem do lugar sagrado pondo a mão naquilo que é intocável. A técnica moderna somente aumentou o alcance da mão até que consegue plantar orelhas humanas nas costas de ratos de laboratório. Como sempre, a técnica precisa do homem para mostrar seus potenciais e o homem precisa da técnica para aumentar sua potência. $\mathrm{O}$ dispositivo técnico não é, então, um Deus ex-maquina que agisse sem a participação humana. No entanto, o homem não pode manipular tecnicamente o mundo ao seu bel prazer. O dispositivo técnico permite certos movimentos e inibe outros. A manipulação ocorre dentro dos padrões de possibilidades do dispositivo técnico; este dispositivo pode ser interpretado como um fenômeno sóciotécnico, sim, mas não por isso torna-se uma construção da autoria exclusiva do homem. 


\section{(7) fabricação (industrialização)}

A fabricação de artefatos em larga escala é simplesmente o cerne da sociedade industrial. Ela pressupõe manipulação, funcionalização, quantificação, homogeneização, materialização e racionalização. A fábrica com a máquina a vapor no seu centro tornou-se cedo o símbolo da sociedade (capitalista) moderna porque representa historicamente uma manifestação já bastante madura daquilo que chamamos dispositivo técnico. Com a fabricação surge a serialização da produção; i.e., a peça única elaborada pelo artesão está sendo substituída pela cópia seqüencial. Novidades emergem com a descoberta das qualidades diferenciadas dos materiais; novidades que no berço do seu surgimento já são condenadas a servir de matrizes para outras seqüências de repetições.

Com a interconexão e aglomeração das fábricas transformamse todas as relações sociais até que a sociedade se apresenta como um gigantesco sistema fabril, i.e. como sociedade industrial. Com a globalização mudam os parâmetros para a alocação ideal de recursos. Antigos centros da industrialização perdem partes das suas vantagens comparativas e reestruturam o seu sistema produtivo. A fábrica do mundo globalizado não une mais todos os seus componentes no mesmo galpão, a fábrica mesma está sendo globalizada e estende hoje o mecanismo da fabricação sobre todos os continentes. O mundo fabricado torna-se apesar da sua artificialidade progressivamente a segunda natureza do homem, homem que se assemelha cada vez mais aos tentáculos de um coral, na ponta de petrificações milenares resultado das suas próprias atividades.

\section{(8) imposição (antropocentrismo)}

A técnica moderna é sempre sócio-técnica. Enquanto tal, ela mostra os traços elementares da sociedade no seu design. Estruturas técnicas altamente centralizadas (por causa de necessidades produtivas e administrativas) espelham sociedades que se auto-organizaram segundo os critérios da grande máquina (MUMFORD, 1966). Também vale o inverso: complexos técnicos centralizados "produzem" estruturas sociais com poucas margens para a liberdade individual. Usinas nucleares nunca podem ser abertas para a participação popular; tampouco podem ser desligadas na 
hora quando uma agremiação política acha oportuna. O dispositivo técnico que se impõe à natureza, prolonga essa imposição para dentro do corpo social. Esta imposição é consequiência direta da tensa relação entre sujeito e objeto, entre o antropos moderno e seu habitat natural, submetido a disposições técnicas unilaterais.

\section{(9) aceleração (modernização)}

Nosso tempo é o tempo que é próprio do ser humano; ele é o tempo da nossa vida; é o tempo lento do nosso amadurecimento; é o tempo do luto e o tempo que o novo amor precisa para desabrochar. Os "tempos próprios" aparecem, de forma desvinculada, em diversas disciplinas acadêmicas; necessário, então, consultar os físicos para saber mais sobre o tempo do espaço, seja ele aquém ou além daquele espaço que os sentidos do homem ainda alcançam; indispensável, também, perguntar aos filósofos para ouvir as suas indagações sobre o tempo e para tomar conhecimento das suas primeiras tentativas de pensar a técnica; a história, enquanto ciência, nos fala sobre a evolução dos artefatos e, junto com a antropologia, nos fornece informações e explicações sobre o uso culturalmente distinto da técnica e a existência, nas diversas sociedades humanas, de regimes temporais diferentes; sobre os tempos próprios da vida e seus ciclos de reprodução nos informa a biologia que, também, contribuiu significativamente para desvendar o funcionamento da vida sem, todavia, poder revelar seu mistério. O dispositivo técnico ignora os tempos próprios e acelera qualquer processo de mudança.

\section{(10) deslocação (globalização)}

A modernidade técnica nasceu por causa da contingência histórica na Europa. Os ingleses foram disciplinados precocemente por ela e, por causa deste disciplinamento, num doloroso processo, descrito por Norbert Elias e Thompson, esperam hoje, enfileirados, o próximo ônibus. O dispositivo técnico desdobrou primeiro na Europa, mais precisamente na Inglaterra, França e Alemanha, as suas forças revolucionárias; quem queria negar isso? Não obstante, leva o caráter "u-tópico" da modernidade técnica, cada vez mais a um deslocamento da sua dinâmica inicial. Há 
muito, uma ex-colônia da Inglaterra dá as cartas na política mundial e há muito mostram países como Japão que o racionalismo ocidental não precisa propriamente do Ocidente para vigorar. O dispositivo técnico não é uma criação ou invenção européia, apesar do fato que foram europeus que fizeram com ele as suas primeiras experiências, desencadeando assim um processo de mudanças com dimensões globais. Não, o próprio dispositivo técnico tende a universalização por causa do seu caráter homogeneizador e acelerador. Os "conquistadores", “colonizadores", "imperialistas", "capitalistas" etc. somente emprestaram suas fisionomias à uma dinâmica presente neste dispositivo. Combater eles, assim dizer, "pessoalmente”, é uma luta que levou na maioria dos casos a uma aceleração dos processos de modernização técnica e não a realização de uma alternativa histórica. A oposição moderna ao dispositivo técnico levou sempre a sua imitação. Freqüentemente chamamos esse processo de desenvolvimento.

\section{(11) reprodução}

Já no bojo da fabricação, encontramos a repetição, a serialização e a cópia. Reproduzir significa tudo isso e mais um passo decisivo além. Com a fabricação, alcança o dispositivo técnico as precondições da reprodução das condições de vida do ser humano. A reprodução engloba cada vez mais os ciclos reprodutivos vitais, desde os processos metabolísticos até a criação e procriação de descendentes. Reproduzir tecnicamente a vida fecha 0 circuito entre artificialidade e naturalidade. A natureza torna-se técnica e a técnica torna-se natureza. Que essa equação não fecha ainda perfeitamente, é um desafio ao gosto do dispositivo técnico.

\section{(12) substituição}

O que não se encaixa perfeitamente pode ser substituído. Também aquele que foi gasto pode ser trocado por uma peça nova. Finitude e infinitude, mortalidade e imortalidade, momento e eternidade, configuram entre os grandes temas da Teologia, da Filosofia, da Poesia e da Arte e evocam desde os tempos remotos o homem para dar as respostas mais diversas. A técnica moderna, de sua maneira, acessa esses temas; ela injeta o máximo possível de "tempo do mundo" para dentro do "tempo da vida", sem, contudo, 
poder resolver o problema da mortalidade; ela acelera o aproveitamento do tempo da vida e prolonga o tempo à disposição substituindo aquele que foi gasto proteticamente. No horizonte da modernidade técnica aparece, desta maneira, o homo proteticus que é o homo faber aplicando a força inovadora da técnica moderna a si mesmo.

\section{(13) construção}

Não surpreende que o mundo aparece nos olhos do técnico moderno como uma gigantesca construção. Isso não foi sempre assim? O homem não denominava durante milhares de anos o mundo como uma criação? Acontece que a criação e a construção apontam nas direções diversas. A criação do mundo pressupõe um Deus criador, que fez o mundo conforme sua vontade misteriosa. O mundo construído já é um mundo sem Deus. $\mathrm{O}$ construtor do mundo técnico é o próprio homem que não aceita a sacralidade daquilo que está a sua mão. Cada vez mais expande o dispositivo técnico suas competências e apresenta tudo, desde os valores morais até os laços emocionais mais delicados, como construidos. Até a sexualidade aparece, curiosamente, como uma construção, senão como uma opção a ser "construida" pelo sujeito. Índio é quem se declara, i.e., "construiu", índio. E o problema, antes de existir, tem que ser "construído". Sentimos como o dispositivo técnico começa perder a noção de realidade e parte na direção de horizontes inusitados. As possibilidades inexploradas são, mais uma vez, o atrator contingens da sua movimentação.

\section{(14) virtualização (realidade)}

Com a virtualização chega o dispositivo técnico a um dos extremos das suas possibilidades. O virtual é algo bastante real, como os bancos virtuais, por exemplo, mostram. Não obstante, a virtualização transcende essa realidade e mescla-a com algo que conhecemos até agora somente do mundo da fantasia. A realidade fantasiosa parece até superar o paradigma da materialização inerente ao dispositivo técnico, pois ela é permeada pela imaterialidade de algo não realmente existente. Contudo, esgotado o padrão de possibilidades do virtual, encaramos mais tarde, querendo ou não, aquilo que a virtualização somente transforma, mas não consegue 
anular, i.e. a realidade. Assim, a guerra eletrônica transforma os atiradores em jogadores, pois, no lugar onde a bala perfura o corpo humano, rasga o véu do virtual e sente-se a dor da morte violenta chegar. No momento, antes que a morfina faça seu efeito, algo quer nos lembrar do essencial e nós queremos trocar essa maca ensopada de sangue, nosso sangue, por um outro jogo, menos real. Mas, dessa vez, somente escutamos uma campainha, que lembra da campainha do nosso celular e um aviso na tela informa: game over!

\section{(15) plasticidade (resistência)}

A ciência almeja a "transparência” das coisas, dos corpos e das almas. Somente quando os fenômenos são "transparentes" consegue o dispositivo técnico realizar todas as suas possibilidades, todo seu trabalho. Mais do que transparência procura o dispositivo técnico em tudo a sua plasticidade, as suas possibilidades ocultas, explorando assim a contingência do Ser. A técnica moderna transforma tudo, tendencialmente, em "plástico". A passagem da "plástica" ao "plástico" é exatamente o caminho percorrido historicamente entre a techné e a técnica moderna. Ser "plástico" significa, ser cientificamente decifrável e acessível às manipulações técnicas. Que "a plástica” nos fala hoje, também, sobre uma técnica cirúrgica em prol da substituição daquilo que foi gasto, não surpreende aquele que conhece o dispositivo técnico.

\section{(16) emergência (desaparecimento)}

Existe um sentido ante rem, é aquele velho sentido visado da qual nos fala Max Weber. Este sentido, atribuído pelo ator às suas próprias ações pode nem sempre se concretizar; outros atores agem e acontecimentos inesperados surgem no meio do caminho. Também, algo que aconteceu e se desenrolou de forma desapercebida pode ganhar um significado post rem, um sentido posteriormente. Interpretando a modernidade técnica do resultado das suas ações conjuntas leva a outros resultados do que interpretá-la a partir das intenções dos seus atores. Podemos até perguntar se faz muito sentido julgar toda uma época a partir da sua autocompreensão e seus objetivos declarados. Ainda é cedo, mas condensando os dados sobre 
diversos problemas ambientais e epidemiológicos e cruzando estes com informações sobre os arsenais de armas biológicas, químicas e nucleares surge sem grandes esforços a impressão que o objetivo não-declarado da modernidade técnica, é o seu próprio desaparecimento. Contra esta perspectiva levanta-se o otimismo da vida que repulsa cenários que contradizem seus próprios interesses. $\mathrm{E}$, também, o dispositivo técnico não é tão monolítico como o cenário catastrófico pressupõe. A técnica moderna tem um relação ambígua (no mínimo ambígua) com o futuro e não revela de antemão seu percurso. Não obstante, estamos frente ou melhor, no meio, de um evento histórico que revela o caráter emergencial do dispositivo técnico. A palavra emergência empregamos aqui no seu sentido duplo: 1 . do emergir de algo novo, algo que promete (se não a salvação, no mínimo novidades); este emergir rompe com estruturas velhas e conhecidas, acompanhá-lo exige pensar na altura e 2. essa emergência da modernidade técnica é cheio de imponderações, riscos em sentido amplo, e requer a solução de inúmeros problemas com urgência. Entre uma emergência e a outra, vivemos, pensamos e não temos escolha: o dispositivo técnico acelera o caráter contingente do mundo moderno e obriga os modernos, que somos nós, a fazer escolhas entre as múltiplas possibilidades.

\section{REFERÊNCIAS}

AQUINO, Tomás de. Os Pensadores. Bauru: Nova Cultural, 1996.

BAUMAN, Zigmunt. Modernidade e Ambivalência. Rio de Janeiro: Zahar, 1999.

BECK, Ulrich. Risikogesellschaft. Frankfurt: Suhrkamp, 1986.

BECK, Ulrich; GIDDENS, Anthony; LASH, Scott. Reflexive Modernization - Politics, Tradition and Aesthetics in the Modern Social Order. Stanford: Stanford University Press, 1994.

BLUMENBERG, Hans. Lebenszeit und Weltzeit. Frankfurt: Surkamp, 1986.

BRÜSEKE, Franz Josef. A técnica e os riscos da modernidade. Florianópolis: Ufsc, 2001. 
BRÜSEKE, Franz Josef. A descoberta da contingência pela teoria social. 2002

BRÜSEKE, Franz Josef. Mística, Magia e Técnica. In: Política e Sociedade, v. 1; n.4, Florianópolis, 2004.

HABERMAS, Jürgen. Erkenntnis und Interesse. In: Habermas, J. Technik und Wissenschaft als Ideologie. Frankfurt: Suhrkamp, 1965/1968 p. 146-167

HABERMAS, Jürgen. Die Zukunft der menschlichen Natur. Auf dem Weg zu einer liberalen Eugenik? Frankfurt: Suhrkamp, 2001/2002.

HEIDEGGER, Martin. Was heisst Denken?

HEIDEGGER, Martin. Der Satz vom Grund. Stuttgart: Neske, $1957 / 1992$.

HEIDEGGER, Martin. Nietzsche, 2.vls. Stuttgart: Neske, 1961.

HEISENBERG, Werner. Ordnung der Wirklichkeit. München: Piper, 1939/1989.

HOFFMANN, Arnd (2005): Zufall und Kontingenz in der Geschichtstheorie. Mit zwei Studien zu Theorie und Praxis der Sozialgeschichte. ISBN 3-46503369-8. Studien zur europäischen Rechtsgeschichte vol. 184

JOAS, Hans. Kontingenzbewußtsein. Der Erste Weltkrieg und der Bruch im Zeitbewußtsein der Moderne, in: Petra Ernst/Sabine Haring/Werner Suppanz (Hg.), Aggression und Katharsis. Der Erste Weltkrieg im Diskurs der Moderne. Wien 2004, S. 43-56

JÜNGER, Ernst. Der Arbeiter

KLEPPER, Beate. Gnade und Erziehung Historisch-systematische Untersuchungen zu einer pädagogischen Kontingenzbewältigungsstrategie. ISBN 3-89913-309-9 Erziehung, Schule, Gesellschaft Band 29, 2003.

KOSELLECK, Reinhart. Vergangene Zukunft. Frankfurt: Suhrkamp, 1979.

LISK, M.Th. Fülleprinzip oder echter Indeterminismus? Zu Thomas' Begriff 
der Kontingenz , in: Disputatio Philosophica 1, 2000, S. 105-124 LUHMANN, Niklas. Soziologie des Risikos. Berlin, New York: Walter de Gruyter, 1991.

LUHMANN, Niklas. Observaciones de la modernidad. Racionalidad y contingencia en la sociedad moderna. Barcelona: Paidós, 1992/1997.

LYOTARD, Françoise. A condição pós-moderna. Rio de Janeiro: José Olímpio, 1979/1986.

MAFFESOLI, Michel. Sobre o Nomadismo. Vagabundagens pósmodernas. Rio de janeiro/São Paulo: Record, 1997/2001.

MAKROPOULOS, Michael. Möglichkeitsbändigungen. Disziplin und Versicherung als Konzepte zur sozialen Steuerung von Kontingenz. In: Soziale Welt, 41, 1990, p. 407-423.

MAKROPOULOS, Michael. Modernität und Kontingenz. München: Fink, 1997.

MAKROPOULOS, Michael. Modernität als Kontingenzkultur. Konturen eines Konzepts. In: Gerhart von Graevenitz / Odo Marquard (Hg.), Kontingenz (Poetik und Hermeneutik, 17), München, Fink, 1998, p. 5579.

MAKROPOULOS, Michael. Historische Kontingenz und soziale Optimierung. In: Rüdiger Bubner; Walter Mesch (orgs.). Die Weltgeschichte - das Weltgericht? (Akten des Internationalen Hegel-Kongresses 1999), Stuttgart: Klett-Cotta 2000, p. 77-92

MAKROPOULOS, Michael. Kontingenz und Selbstungewißheit. Bemerkungen zu zwei Charakteristika moderner Gesellschaften. In: Gesa Dane et al. (Hg.), Anschlüsse - Versuche nach Michel Foucault.Tübingen, edition diskord, 1985, p. 17-26.

MARCUSE, Herbert. Industrialisierung und Kapitalismus im Werk Max Webers; in: Kultur und Gesellschaft II, Frankfurt: Suhrkamp, 1965.

MUMFORD, Lewis. Myth of Machine. 
NEGT, Oskar. Der Kampf um die Arbeitszeit ist ein Kampf um die Lebenszeit. In: Rainer Zoll. Zerstörung und Wiederaneignung von Zeit. Frankfurt: Suhrkamp, 1988, p. 531-543.

PERLER, Dominik. "Notwendigkeit und Kontingenz. Das Problem der 'futura contingentia' bei Wilhelm von Ockham", in: Die Philosophie im 14. und 15. Jahrhundert. In memoriam Konstanty Michalski (1879-1947), hrsg. von O. Pluta, Amsterdam: Grüner 1988, 39-65

RORTY, Richard. Contingência, Ironia e Solidariedade. Lisboa: Presença, 1989/1992.

SCHULZE, Gerhard. Die Erlebnisgesellschaft. Kultursoziologie der Gegenwart. Frankfurt: Campus, 1992.

SLOTERDIJK, Peter. Regras para o Parque Humano. São Paulo: Estação Liberdade, 1999/2000.

SÖDER, J. Kontingenz und Wissen: Die Lehre von den futura contingentia bei Johannes Duns Scotus. Theologie und Philosophie 74 (1999):426-9

SPENGLER, Oswald. O Homem e a Técnica. Lisboa: Guimarães Editores, 1931/1993.

SPENGLER, Oswald. Der Untergang des Abendlandes. 